\title{
Orthostatic increase of respiratory gas exchange in hyperventilation syndrome
}

\author{
L Pekka Malmberg, Klaus Tamminen, Anssi R A Sovijärvi
}

\begin{abstract}
Background-Hyperventilation syndrome (HVS) is a common disorder which is difficult to diagnose because of somatic symptoms and its episodic nature. In previous studies respiratory alkalosis in arterial blood was often found during orthostatic tests in patients with HVS. The purpose of this study was to assess these orthostatic changes by non-invasive pulmonary gas exchange measurements and to evaluate whether these responses discriminate patients with HVS from healthy subjects.
\end{abstract}

Methods-Respiratory gases were collected with a face mask and pulmonary gas exchange was measured after $10 \mathrm{~min}$ utes at rest and after eight minutes standing upright in 16 patients with HVS and 13 healthy control subjects. In patients with HVS arterial blood samples were also drawn at rest and in the standing position. Results-At rest the variables of respiratory gas exchange did not differ significantly between the groups. As a response to standing, minute ventilation increased in both study groups but significantly more in the patients with HVS (mean difference $5.4 \mathrm{l} / \mathrm{min}(95 \%$ CI 1.1 to 9.6$))$. The changes in end tidal $\mathrm{CO}_{2}$ fraction $\left(\mathrm{FETCO}_{2}\right)$ and in ventilatory equivalents for oxygen $\left(\dot{\mathbf{V}}_{\mathrm{E}} / \dot{\mathrm{V}}_{2}\right)$ and for $\mathrm{CO}_{2}\left(\dot{\mathrm{V}}_{\mathrm{E}} / \dot{\mathrm{V}} \mathrm{CO}_{2}\right)$ during the orthostatic test were also significantly larger in patients with HVS than in healthy controls. During standing FeTCO, was significantly lower (mean difference $-1.1 \mathrm{kPa} ; 95 \% \mathrm{CI}-1.5$ to -0.6$)$ and $\dot{\mathrm{V}} / \dot{\mathrm{V}}_{2}$ (mean difference 18.4 ; 95\% CI 7.7 to 29.0 ) and $\dot{\mathrm{V}} \mathrm{E} / \dot{\mathrm{V}}_{\mathrm{CO}_{2}}$ (mean difference $11.7 ; 95 \% \mathrm{CI}$ 4.8 to 18.6 ) were significantly higher in HVS patients than in healthy controls. By using the cut off level of $4 \%$ for $\mathrm{FETCO}_{2}$ the sensitivity and specificity of the test to discriminate HVS were $87 \%$ and $77 \%$, respectively, and by using the cut off level of 37 for $\dot{V} E / \dot{V}_{2}$ they were $93 \%$ and $100 \%$, respectively. In the HVS patients arterial $\mathrm{PCO}_{2}$ and $\mathrm{FeTCO}_{2}$ were closely correlated during the orthostatic test $(r=0.93$, p<0.0001).

Conclusions-As a response to change in body position from supine to standing, patients with HVS have an accentuated increase in ventilation which distinguishes them from healthy subjects. These findings suggest that non-invasive measurements of pulmonary gas exchange during orthostatic tests are useful in the clinical evaluation of patients with hyperventilation disorders.

(Thorax 2000;55:295-301)

Keywords: hyperventilation syndrome; diagnosis; ventilatory gas exchange; orthostatic test; blood gas analysis

Hyperventilation is defined as a state of alveolar ventilation in excess of metabolic requirements resulting in decreased arterial partial pressure of carbon dioxide $\left(\mathrm{PaCO}_{2}\right)$. When hyperventilation occurs chronically or in recurrent episodes and is associated with somatic (respiratory, neurological, intestinal) or psychological (anxiety) symptoms, the clinical entity is called hyperventilation syndrome (HVS). ${ }^{1}$ HVS and panic disorder are strongly associated; most patients show characteristics of both disorders, but they generally lack findings of any underlying organic disease. ${ }^{23}$

The correct diagnosis of HVS is of great clinical importance since at least $5-10 \%$ of general medical outpatients have been reported to suffer from this syndrome and, due to a variety of somatic symptoms, the risks of misdiagnosis are considered to be high. ${ }^{4}$ Several diagnostic tools have been described since only few patients with HVS are actually seen during a typical attack. The reproduction of the HVS symptoms during voluntary hyperventilation has been suggested as a basis for the diagnosis, ${ }^{5}$ but recent studies have shown that the test lacks both sensitivity and specificity. ${ }^{6}$ Even the validity of the test has been questioned, since the symptoms in HVS often precede events of hypocapnia rather than are a consequence of them. ${ }^{7}$

Symptoms and hyperventilation may also be provoked in susceptible patients by exercise, ${ }^{8-10}$ mental stress, ${ }^{9}$ and by pharmacological challenges. ${ }^{11}{ }^{12}$ In our earlier studies respiratory alkalosis in arterial blood was frequently found during orthostatic tests in patients with HVS, ${ }^{8}$ suggesting that change in body posture provokes these patients to have abnormal ventilatory responses.

The aim of the present study was to assess the ventilatory responses of patients with HVS when changing the body position from supine to standing. We also compared these results with those of healthy subjects to evaluate whether the orthostatic changes in pulmonary gas exchange discriminate patients with HVS.

\section{Methods}

The anthropometric and lung function data of the patients and subjects are shown in table 1 . Sixteen patients (eight women) with diagnosed HVS, but without signs of underlying cardio-
Revised version received

Accepted for publication

13 December 1999 
Table 1 Anthropometric and mean (SE) lung function data of healthy controls and patients with HVS

\begin{tabular}{lll}
\hline & Controls & HVS \\
\hline No. & 13 & 16 \\
Male/female & $5 / 8$ & $8 / 8$ \\
Age (years) & $39(4)$ & $46(3)$ \\
Weight (kg) & $73(3)$ & $80(4)$ \\
Body mass index & $24(1)$ & $28(1)^{\star}$ \\
Height (cm) $_{\text {FEV }}(1)$ & $174(3)$ & $170(2)$ \\
FEV $_{1}(\%$ pred) & $4.2(0.3)$ & $3.8(0.2)$ \\
FVC (1) & $108(4)$ & $100(3)$ \\
FVC (\% pred) & $5.1(0.4)$ & $4.5(0.3)$ \\
\hline
\end{tabular}

$\mathrm{HVS}=$ hyperventilation syndrome; $\mathrm{FEV}_{1}=$ forced expiratory volume in one second; FVC = forced vital capacity.

${ }^{\star} \mathrm{p}<0.05$ compared with controls (unpaired $t$ test).

respiratory disease, were selected for the study. The basis for the HVS diagnosis was the history of recurrent or episodic dyspnoea, air hunger, dizziness, or paraesthesiae, and the detection of respiratory alkalosis $(\mathrm{pH}>7.45$ and $\mathrm{PaCO}_{2}<4.7 \mathrm{kPa}$ ) in arterial blood during symptoms of hyperventilation. Patients with a history of physician diagnosed asthma or ischaemic heart disease, with or without regular medication, were excluded from the study. None of the patients included used any cardiorespiratory medication at the time of the study; five $(31 \%)$ of the patients had previously used anxiolytic medication. All patients underwent physical examination, chest radiography, flow-volume spirometry, and cardiorespiratory exercise tests with ECG to exclude any organic cardiorespiratory disease. Bronchial hyperreactivity with histamine provocation tests $^{13}$ and pulmonary diffusing capacity were determined if clinically indicated to exclude asthma and interstitial lung disorders, respectively.

All patients complained of episodic dyspnoea or air hunger. Chest pain (19\%), dizziness $(31 \%)$, gastroenterological symptoms $(19 \%)$, and numbness of the face or fingers (25\%) were also common symptoms. In 11 patients $(69 \%)$ palpitations, sweating, trembling, dryness of the mouth or other symptoms of overactivity of the autonomic nervous system were also present, suggestive of panic disorder. ${ }^{14}$

Thirteen healthy non-smoking subjects (eight women) without any cardiorespiratory symptoms or signs volunteered as controls. They all showed normal findings in physical examination, resting ECG, and in flow-volume spirometric tests.

Informed consent was obtained from every patient and subject and the study was approved by the ethics committee of the Department of Pulmonary Medicine at Helsinki University Central Hospital.

Forced expiratory volume in one second $\left(\mathrm{FEV}_{1}\right)$, forced vital capacity (FVC), the ratio of $\mathrm{FEV}_{1}$ to $\mathrm{FVC}$, and the maximal expiratory flow at $50 \%$ of FVC $\left(\mathrm{MEF}_{50}\right)$ were determined with a rolling seal spirometer (CPI 220, Cardiopulmonary Instruments, Houston, USA) connected to a microcomputer system (Medikro 202, Kuopio, Finland), according to European recommendations. ${ }^{15}$ The results from the envelope curve of at least three superimposed forced expiratory flow-volume loops were recorded.
The orthostatic tolerance tests were performed in a quiet, dimly lit laboratory room during office hours. Before orthostatic testing the brachial artery of the patient was cannulated under local anaesthesia (1\% lidocaine). Thereafter, two nurses conducted the test and recordings. After the patient had rested for 10 minutes in the supine position a face mask (Rudolf series 7910, Hans Rudolf Inc, Kansas City, USA) was tightly attached and connected to an automatic gas exchange analyser with a mixing chamber (Ergo-Oxyscreen, Erich Jaeger, Würzburg, Germany). The mask and the valve system had a dead space of $185 \mathrm{ml}$. The patients were allowed to breathe via the mask in the supine position for five minutes to adapt for the increased dead space; minute ventilation $(\dot{\mathrm{V}} \mathrm{E})$, breathing frequency $(\mathrm{BF})$, oxygen consumption $\left(\dot{\mathrm{V}}_{2}\right)$, carbon dioxide outflow $\left(\dot{\mathrm{V}} \mathrm{CO}_{2}\right)$, respiratory exchange ratio (RQ), ventilatory equivalents for $\mathrm{O}_{2}\left(\dot{\mathrm{V}} / \dot{\mathrm{V}}_{2}\right)$ and for $\mathrm{CO}_{2}\left(\dot{\mathrm{VE}} / \mathrm{V}_{\mathrm{CO}}\right)$, and end expiratory tidal $\mathrm{CO}_{2}$ fraction $\left(\mathrm{FETCO}_{2}\right)$ were then recorded over a 30 second interval and an arterial blood sample for blood gas analysis $\left(\mathrm{PaO}_{2}, \mathrm{PaCO}_{2}, \mathrm{pH}\right.$, base excess) was simultaneously drawn via the cannula. Heart rate (HR) and blood pressure (BP) were also recorded at this stage.

After the resting period the patients were asked to rise and to stand still and unsupported in the upright body position for eight minutes. ${ }^{16}$ During this phase the room was kept quiet and no conversation was allowed. Respiratory gas exchange and ECG (HR) were continuously monitored and, after standing for eight minutes, the blood pressure was determined and an arterial blood sample was drawn from the brachial cannula. The respiratory gas exchange results at this time were determined from the gas concentrations in the mixing chamber during the last 30 seconds in the upright body position. In healthy controls the study design was identical to that in the patients with HVS except that arterial cannulation was not performed for ethical reasons, and therefore no arterial blood samples were taken.

In paired comparisons of test results between body positions the Wilcoxon signed rank test was used, and in comparisons between study groups the Mann-Whitney U test was applied. For correlation analysis the Pearson correlation coefficient was calculated.

\section{Results}

RESPIRATORY GAS EXCHANGE RESPONSES

The results of pulmonary gas exchange at rest and during the orthostatic test in healthy subjects and in patients with HVS are shown in table 2. The individual responses of $\dot{\mathrm{V}}_{\mathrm{E}}$, $\dot{\mathrm{VE}} / \dot{\mathrm{V}}_{2}, \dot{\mathrm{VE}} / \dot{\mathrm{V}}_{\mathrm{CO}_{2}}$, and $\mathrm{FETCO}_{2}$ during the orthostatic test are illustrated in figs 1,2, 3 and 4 , respectively. The resting values were not significantly different between the groups. In both groups the mean $\mathrm{FETCO}_{2}$ was within the normal range but in individual patients and subjects the FETCO $_{2}$ at rest was slightly low. During the orthostatic test the controls did not show an increase in BF but their $\dot{V}_{E}$ increased significantly $(p=0.01)$. In the HVS patients both BF $(\mathrm{p}=0.005)$ and $\dot{\mathrm{V}}_{\mathrm{E}}(\mathrm{p}=0.001)$ increased sig- 
Table 2 Respiratory gas exchange and circulatory responses during orthostatic tolerance test at rest and after 8 minutes standing in healthy controls and in patients with HVS

\begin{tabular}{|c|c|c|c|c|c|c|}
\hline & \multicolumn{3}{|c|}{ Controls $(n=13)$} & \multicolumn{3}{|c|}{ HVS patients $(n=16)$} \\
\hline & At rest & Standing & Change & At rest & Standing & Change \\
\hline $\mathrm{BF}(/ \mathrm{min})$ & $14.5(0.8)$ & $14.9(0.9)$ & $0.4(-0.5$ to 1.3$)$ & $14.0(1.1)$ & $17.9(1.1)$ & $3.9(1.5 \text { to } 6.2)^{\star}$ \\
\hline$\dot{\mathrm{V}} \mathrm{E}(1 / \mathrm{min})$ & $8.1(0.6)$ & $9.3(0.6)$ & $1.2(0.5$ to 1.9$)$ & $7.7(0.9)$ & $14.2(1.8)^{\star}$ & $6.5(3.5 \text { to } 9.6)^{\star}$ \\
\hline $\mathrm{RQ}$ & $0.79(0.03)$ & $0.77(0.02)$ & $-0.02(-0.06$ to 0.09$)$ & $0.87(0.04)$ & $0.91(0.03)^{\star}$ & $0.04(-0.02$ to 0.10$)$ \\
\hline $\mathrm{FETCO}_{2}(\%)$ & $4.27(0.12)$ & $4.18(0.08)$ & $-0.09(-0.26$ to 0.09$)$ & $4.18(0.13)$ & $3.12(0.16)^{\star \star \star}$ & $-1.05(-1.30 \text { to }-0.81)^{\star \star \star}$ \\
\hline$\dot{\mathrm{V}} \mathrm{E} / \dot{\mathrm{V}}_{2}$ & $31.0(1.2)$ & $32.2(1.0)$ & $1.2(0.5$ to 2.0$)$ & $36.4(1.9)$ & $50.6(3.9)^{\star \star \star}$ & $14.3(8.5 \text { to } 20.0)^{\star \star}$ \\
\hline$\dot{\mathrm{VE}} / \dot{\mathrm{V}} \mathrm{CO}_{2}$ & $39.2(1.7)$ & $41.8(1.3)$ & $2.7(1.3$ to 4.0$)$ & $41.9(1.3)$ & $53.6(2.4)^{\star \star \star}$ & $11.7(7.2 \text { to } 16.2)^{\star}$ \\
\hline $\mathrm{HR}(/ \mathrm{min})$ & $65.0(1.8)$ & $77.1(2.9)$ & $12.1(7.8$ to 16.3$)$ & $72.9(1.9)^{\star}$ & $93.4(3.7)^{\star \star}$ & $20.5(15.3 \text { to } 25.7)^{\star}$ \\
\hline Systolic BP (mm Hg) & $122(4.2)$ & $125(3.9)$ & $4(-1$ to 8$)$ & $135(4.3)^{\star}$ & $137(5.9)$ & $1(-7$ to 9$)$ \\
\hline
\end{tabular}

${ }^{\star} \mathrm{p}<0.05 ;{ }^{\star \star} \mathrm{p}<0.01 ;{ }^{\star \star \star} \mathrm{p}<0.001$ compared with controls (Mann-Whitney U test).

The results within groups are expressed as mean (SE) and the changes as mean ( $95 \%$ confidence intervals).

$\mathrm{BF}=$ breathing frequency; $\dot{\mathrm{VE}}=$ minute ventilation; $\mathrm{RQ}=$ respiratory exchange ratio; $\mathrm{FETCO}_{2}=$ end expiratory tidal $\mathrm{CO}_{2}$ fraction; $\dot{\mathrm{V}}_{\mathrm{E}} / \dot{\mathrm{V}}_{2}, \dot{\mathrm{V}}_{\mathrm{E}} / \dot{\mathrm{V}}_{\mathrm{CO}}=\mathrm{ventilatory}$ equivalents for $\mathrm{O}_{2}$ and $\mathrm{CO}_{2} ; \mathrm{HR}=$ heart rate; $\mathrm{BP}=$ blood pressure.
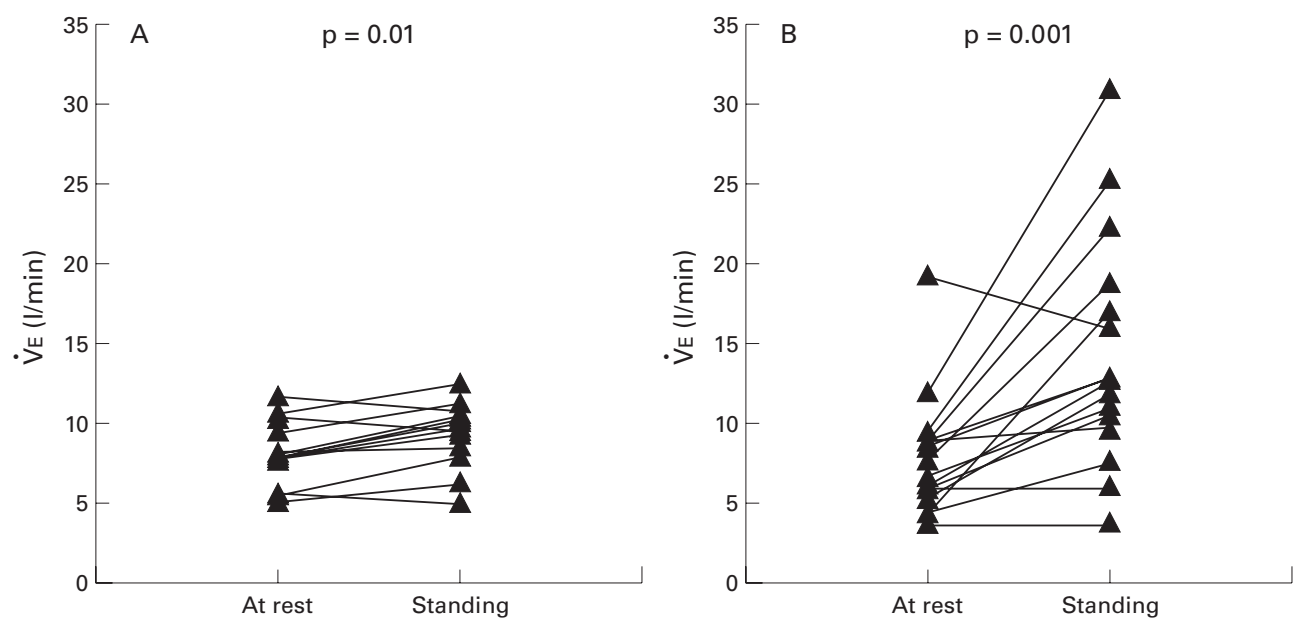

Figure 1 Individual responses of minute ventilation $\left(\dot{V}_{E}\right)$ during the orthostatic test in $(A)$ healthy controls $(n=13)$ and (B) patients with HVS $(n=16)$. The $p$ value refers to the Wilcoxon signed rank test.
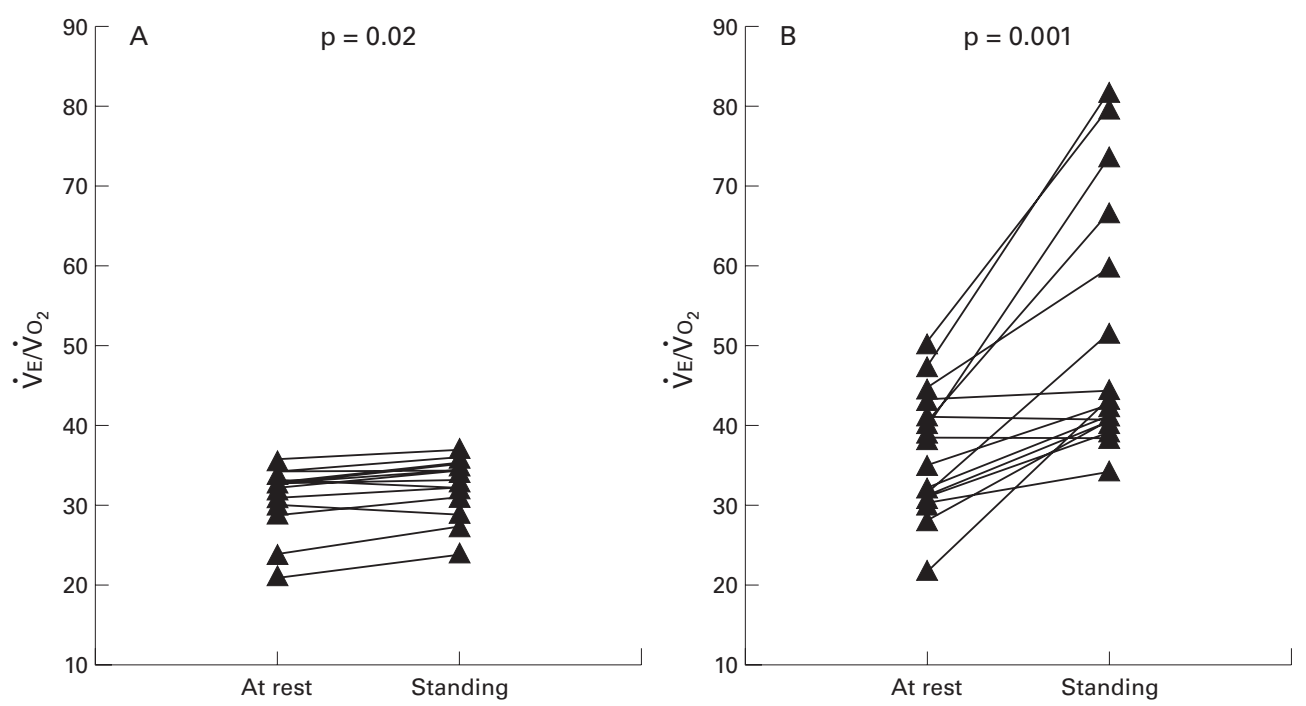

Figure 2 Individual responses of the ventilatory equivalent for oxygen $\left(\dot{V}_{E} / \dot{V}_{\mathrm{O}_{2}}\right)$ during the orthostatic test in $(A)$ healthy controls $(n=13)$ and $(B)$ patients with HVS $(n=16)$. The $p$ value refers to the Wilcoxon signed rank test.

nificantly. RQ did not change markedly in either of the groups, but the patients with HVS had significantly higher values at the standing phase. $\mathrm{FETCO}_{2}$ did not change significantly in healthy subjects but decreased in all the patients with HVS ( $p=0.0004)$. While standing $\mathrm{FETCO}_{2}$ was significantly lower in patients with HVS than in controls (mean difference $-1.1 \mathrm{kPa} ; 95 \% \mathrm{CI}-1.5$ to -0.6$)$. As a response to standing up, $\dot{\mathrm{V}} \mathrm{E} / \dot{\mathrm{VO}}_{2}$ and $\dot{\mathrm{V}} \mathrm{E} / \dot{\mathrm{V}}_{\mathrm{CO}_{2}}$ increased significantly in both groups. This change was, however, significantly larger in the patients with HVS than in the healthy subjects (mean difference 13.0 (95\% CI 5.2 to 20.8) for $\dot{\mathrm{V}} \mathrm{E} / \dot{\mathrm{V}}_{2}$ and mean difference $9.0(95 \%$ CI 2.8 to 15.2 ) for $\dot{\mathrm{V}} \mathrm{E} / \mathrm{V}_{\mathrm{CO}_{2}}$ ).

The sensitivity, specificity, and positive predictivity of respiratory gas exchange variables during the orthostatic tolerance test for discrimination of HVS were evaluated (table 

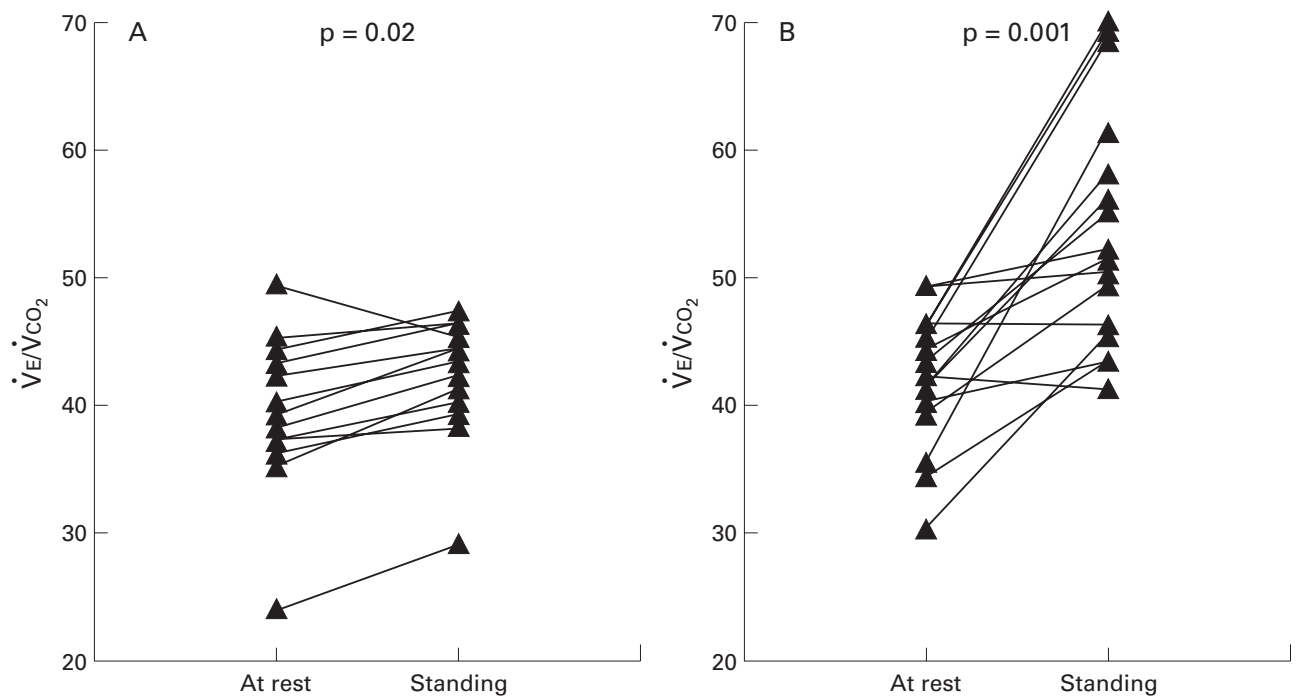

Figure 3 Individual responses of the ventilatory equivalent for carbon dioxide $\left(\dot{V}_{E} / \dot{V}_{\mathrm{CO}_{2}}\right)$ during the orthostatic test in $(A)$ healthy controls $(n=13)$ and $(B)$ patients with HVS $(n=16)$. The $p$ value refers to the Wilcoxon signed rank test.
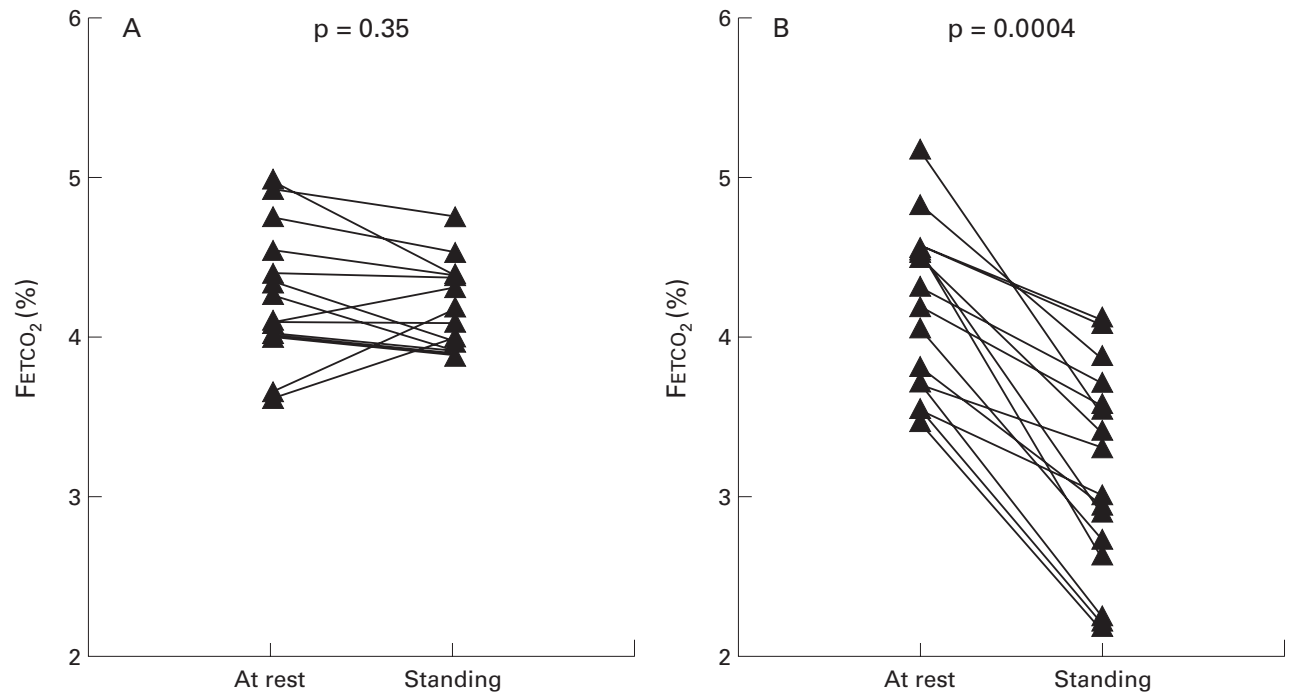

Figure 4 Individual responses of end expiratory tidal $\mathrm{CO}_{2}$ fraction $\left(\mathrm{FETCO}_{2}\right)$ during the orthostatic test in $(A)$ healthy controls $(n=13)$ and $(B)$ patients with HVS $(n=16)$. The $p$ value refers to the Wilcoxon signed rank test.

3). Depending on the variable chosen, the sensitivity ranged from $69 \%$ to $93 \%$ and the specificity from $77 \%$ to $100 \%$.

ARTERIAL BLOOD GAS RESPONSES

Fourteen patients with HVS (87\%) had hypocapnia $\left(\mathrm{PaCO}_{2}<4.7 \mathrm{kPa}\right)$ with or without respiratory alkalosis $(\mathrm{pH}>7.45)$ in the arterial blood while standing during the orthostatic test, indicating hyperventilation. As a response to the orthostatic test mean (SE) $\mathrm{PaCO}_{2}$ decreased from $4.6(0.1) \mathrm{kPa}$ to $3.7(0.2) \mathrm{kPa}$ $(\mathrm{p}=0.0006)$ and $\mathrm{pH}$ increased from 7.45 (0.01) to $7.50(0.01)(p=0.001)$.

In the patients with HVS the $\mathrm{FeTCO}_{2}$ during the standing phase correlated closely with the simultaneous $\mathrm{PaCO}_{2}(r=0.93, \mathrm{p}<0.0001$; fig 5); there was also a close relationship between arterial blood $\mathrm{pH}$ and $\dot{\mathrm{V}} / \dot{\mathrm{V}}_{\mathrm{CO}_{2}}(r=0.78, \mathrm{p}=$ $0.0004)$.

CIRCULATORY RESPONSES

HR was significantly higher in the HVS group than in healthy controls both at rest (mean dif-
Table 3 Sensitivity, specificity, and positive predictivity of respiratory gas exchange results (the values while standing and the change from supine to standing) during the orthostatic tolerance test for the diagnosis of HVS

\begin{tabular}{lllll}
\hline Parameter & $\begin{array}{l}\text { Cut off } \\
\text { level }\end{array}$ & $\begin{array}{l}\text { Sensitivity } \\
(\%)\end{array}$ & $\begin{array}{l}\text { Specificity } \\
\text { (\%) }\end{array}$ & $\begin{array}{l}\text { Positive } \\
\text { predictivity } \\
(\%)\end{array}$ \\
\hline $\mathrm{FETCO}_{2}$ & $<4 \%$ & 87 & 77 & 82 \\
$\Delta \mathrm{FETCO}_{2}$ & $<-0.5 \%$ & 81 & 92 & 93 \\
$\dot{\mathrm{V}} / \dot{\mathrm{V}}_{2}$ & $>37$ & 93 & 100 & 100 \\
$\Delta \mathrm{\textrm {V }} / \mathrm{VO}_{2}$ & $>5$ & 75 & 100 & 100 \\
$\dot{\mathrm{V}} / \dot{\mathrm{V}}_{2} \mathrm{CO}_{2}$ & $>47$ & 69 & 100 & 92 \\
$\Delta \dot{\mathrm{V}} / \dot{\mathrm{V}}_{\mathrm{CO}_{2}}$ & $>5$ & 69 & 92 & 92
\end{tabular}

$\mathrm{FETCO}_{2}=$ end expiratory tidal $\mathrm{CO}_{2}$ fraction; $\dot{\mathrm{VE}} / \dot{\mathrm{V}}_{2}, \dot{\mathrm{V}} / \dot{\mathrm{V}}_{\mathrm{CO}_{2}}=$ ventilatory equivalents for $\mathrm{O}_{2}$ and $\mathrm{CO}_{2}$; sensitivity $=$ true positives/(true positives + false negatives) $\%$; specificity $=$ true negatives/(true negatives + false positives) $\%$; positive predictivity $=$ true positives $/$ (true positives + false positives) $\%$.

Estimates are based on test result distributions of patients with HVS $(n=16)$ and healthy controls $(n=13)$.

ference $7.9 \mathrm{bpm}, 95 \%$ CI 1.6 to 14.2 ) and in the standing position (mean difference 16.4 bpm, $95 \%$ CI 4.8 to 27.9 ). The increase in HR as a response to standing up was also 


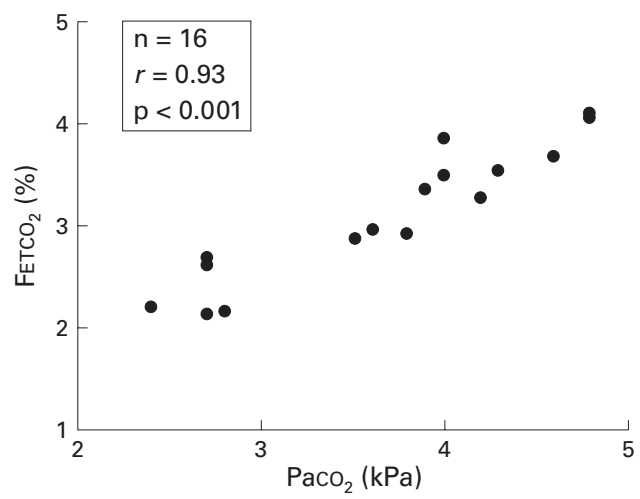

Figure 5 Relationship between arterial partial pressure of $C O_{2}$ and end expiratory tidal $C_{2}$ fraction $\left(F_{E T C O}\right)$ in the patients with HVS $(n=16)$ during the orthostatic test in the standing position.

significantly larger in patients with HVS ( $\mathrm{p}=$ 0.04; table 2). The individual HR responses are illustrated in fig 6. At rest the systolic BP was slightly higher (mean difference $12.5 \mathrm{~mm} \mathrm{Hg}$; $95 \%$ CI 0.3 to $24.7 \mathrm{~mm} \mathrm{Hg}$ ) in the patients with HVS than in healthy controls, but the changes in BP from the supine to standing position did not differ between the groups (table 2).

SYMPTOMS DURING THE TEST

After the orthostatic tests the subjects and patients were asked for symptoms during the test. In the HVS group nine (56\%) complained of dyspnoea, six (38\%) of dizziness, three $(19 \%)$ of numbness of the fingers or face, two $(13 \%)$ of trembling, and one $(6 \%)$ of sweating. In the healthy controls three $(23 \%)$ reported dizziness but none complained of dyspnoea.

\section{Discussion}

This study shows that the change in body posture during the orthostatic test significantly increases pulmonary ventilation in excess of metabolic needs in many patients with HVS. Most of the patients with HVS showed an accentuated ventilatory response which distinguishes them from healthy controls. In HVS patients the consequent respiratory alkalosis or

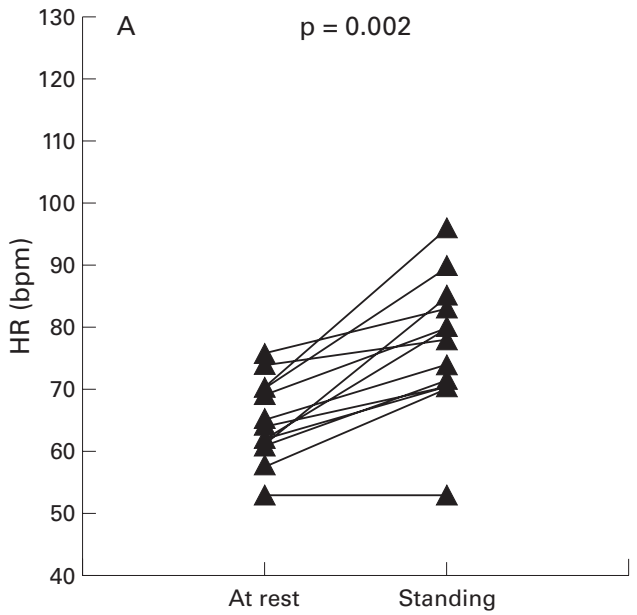

hypocapnia in arterial blood was closely associated with changes in non-invasive pulmonary gas exchange measurements.

In our patients with an established diagnosis of HVS organic cardiorespiratory diseases were excluded to assure that, when present, the hyperventilation was not secondary to any other disease. The gas exchange and circulatory responses were not modified by any medication since the patients were not receiving any drug treatment. The healthy controls were free of cardiorespiratory symptoms and diseases and their anthropometric data did not differ significantly from the HVS patients except for body mass index. The latter is unlikely to explain the different respiratory gas exchange patterns between the groups, since obesity is not known to induce hyperventilation. The study design was not completely identical between the groups as only patients with HVS had an arterial indwelling line placed under local anaesthesia before the test. However, the gas exchange variables at rest (after 15 minutes from arterial cannulation) did not differ between the groups, and therefore the significantly different responses during the orthostatic test are unlikely to result from this intervention.

At rest in both groups some subjects showed somewhat low $\mathrm{FETCO}_{2}$ values (fig 4) but the mean values were within normal limits (table 2). In patients with HVS the correlation between $\mathrm{PaCO}_{2}$ and $\mathrm{FETCO}_{2}$ was good and the calculated mean arterial end tidal difference in $\mathrm{CO}_{2}$ at rest was $0.3 \mathrm{kPa}$ which is close to the expected value ${ }^{17}$; we therefore think that our end tidal measurements were reliable. Due to ethical reasons we did not sample arterial blood from the healthy controls but, based on the end tidal measurements, it is probable that in some of the subjects the test conditions induced slight hyperventilation. Since the control subjects were healthy and did not have any history of respiratory symptoms, we regard their results as a normal range of ventilation during the conditions of the present study. More importantly, the ventilatory responses during standing and not the baseline values were discriminatory between our study groups.

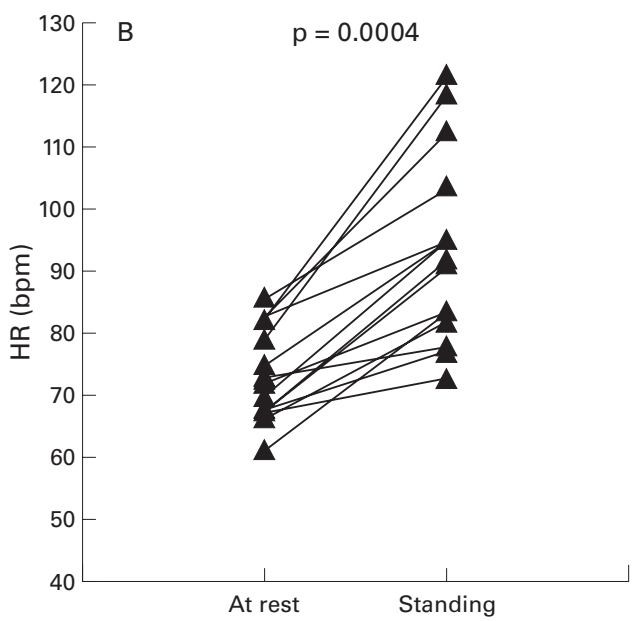

Figure 6 Individual responses of heart rate $(H R)$ during the orthostatic test in $(A)$ healthy controls $(n=13)$ and $(B)$ patients with HVS $(n=16)$. The $p$ value refers to the Wilcoxon signed rank test. 
The reproduction of the symptoms when the subject is instructed to hyperventilate voluntarily has been earlier considered as a cornerstone of the diagnosis of HVS. ${ }^{5}$ However, recent studies have shown that the test lacks both sensitivity and specificity. Gardner et $a l^{9}$ found in their series that six of 17 patients with HVS (35\%) failed to satisfy the diagnostic criteria in the voluntary hyperventilation test. By using several criteria Vansteenkiste et al found concordances of $26-86 \%$ between a positive questionnaire score and the voluntary hyperventilation test. In the study by Hornsveld et al only $34 \%$ of the 85 patients thought by the hyperventilation test to have HVS were considered as true positives and $66 \%$ as false positives. In the latter study even the validity of the test was questioned, since the symptoms in HVS were often found to precede events of hypocapnia rather than being the consequence of them. It therefore seems that the voluntary hyperventilation test cannot serve as a gold standard in identifying patients with HVS.

Presenting symptoms in panic disorder and HVS share many similarities so questionnaires have been designed to identify these patients. We did not use standard questionnaires as earlier studies have suggested that the specificity and sensitivity of symptoms alone in diagnosing hyperventilation syndrome is poor. ${ }^{18} \mathrm{We}$ agree with Cowley and Roy-Byrne ${ }^{2}$ and with Gardner ${ }^{19}$ that the hyperventilation syndrome probably has a more heterogeneous aetiology than panic disorder. This view is also in agreement with the history reported by our patients with HVS since not all reported symptoms suggestive of panic disorder.

Hyperventilation may also be provoked in susceptible patients by exercise, ${ }^{8-10}$ mental stress, ${ }^{9}$ and by pharmacological challenges. ${ }^{11}{ }^{12}$ The orthostatic tolerance test as a provoking stimulus in HVS was originally described in 1981 by Sovijärvi et $a l^{\beta}$ who found respiratory alkalosis in arterial blood gas samples at the standing phase of the test in many patients with HVS. This suggested accentuated orthostatic ventilatory responses.

In the present study we cannot offer definite answers about the mechanisms of the observed orthostatic changes in pulmonary gas exchange in patients with HVS. In our method the added dead space due to the face mask probably also contributed to the increased ventilation. However, the dead space was small and the patients and subjects were allowed to adapt to the mask before resting values were recorded. We therefore believe that the changes in ventilation during the orthostatic test were due to the change in body posture alone. The patients with HVS were not chronically dyspnoeic, nor did they suffer from any cardiorespiratory diseases that would explain them becoming dyspnoeic while standing up. In most, but not all, patients the hyperventilation was associated with dyspnoea while standing. This suggests that other symptoms or mechanisms may also be responsible for the abnormal orthostatic ventilatory responses.

Change in posture from supine to standing has a stimulating effect on the respiratory drive, ${ }^{20}$ probably evoked by baroreceptor dis- charge. In patients with HVS this neural reflex arc may be enhanced due to overactivity of the autonomic nervous system. In agreement with this hypothesis, we also found higher heart rates and accentuated HR responses in patients with HVS. Some of the symptoms reported by the patients such as trembling, sweating, and dizziness may also be signs of dystonic autonomic nervous system.

The history of episodic or recurrent dyspnoea and verified respiratory alkalosis in arterial blood during typical symptoms of hyperventilation were chosen to be the golden standard in diagnosing HVS in the present study. Such information is only rarely available in patients with suspected HVS as only a few patients are seen during a typical attack. Respiratory alkalosis is also a strong indication of hyperventilation in relation to metabolic requirements. It may therefore be argued that the patients selected to enrol in the study probably represent a rather severe state of the disease. Based on this criterion, however, the orthostatic tolerance test appeared to provoke hyperventilation in most but not all patients with HVS. In contrast, the healthy control subjects did not show any gas exchange patterns suggestive of hyperventilation. The sensitivity, specificity, and positive predictivity of the respiratory gas exchange results during the orthostatic test for discrimination of HVS appeared to be better than those reported earlier for the voluntary hyperventilation test. However, due to the small number of patients with verified HVS in the present series, these estimates are only suggestive and, in HVS patients with milder disease, the sensitivity of the test may be lower.

The results indicate that patients with verified HVS have an accentuated response to increase their pulmonary gas exchange over the metabolic needs when changing the body position from supine to standing. Compared with blood gas analyses, non-invasive measurements with capnography or gas exchange analyser provided reliable estimates of gas exchange responses during the test. Since pulmonary gas exchange responses discriminated the patients with HVS with high sensitivity and specificity, their recording during orthostatic tests may be useful in the clinical evaluation of patients with hyperventilation disorders.

Funding: This study was supported by the Finnish Antituberculosis Foundation and the Helsinki University Central Hospital (grant TYH 0033).

\footnotetext{
1 Kerr WJ, Dalton JW, Gliebe PA. Some physical phenomena associated with anxiety states and their relation to associated with anxiety states and their rela

2 Cowley DS, Roy-Byrne PP. Hyperventilation and panic disCowley DS, Roy-Byrne PP. Hypervent
order. Am ₹ Med 1987;83:929-37.

order. Am F Med 1987;83:929-37.
Smoller JW, Pollack MH, Otto MW, et al. State of the art: panic anxiety, dyspnea, and respiratory disease. Theoretical and clinical considerations. Am $\mathcal{F}$ Respir Crit Care Med 1996;154:6-17.

4 Geisler L, Herberg D, Thorspecken R. Diagnose und Therapie des Hyperventilationssyndroms. Fortschr Med 1965;83:463-5.

5 Lewis RA, Howell JBL. Definition of the hyperventilation syndrome. Bull Eur Physiopathol Respir 1986;22:201-5.

6 Vansteenkiste J, Rochette F, Demedts M. Diagnostic tests of hyperventilation syndrome. Eur Respir f 1991;4:393-9.

7 Hornsveld HK, Garssen B, Fiedeldij-Dop MJC, et al. Houble-blind placebo-controlled study of the hyperventilation provocation test and the validity of the hyperventilation syndrome. Lancet 1996;348:154-8.
} 
8 Sovijärvi ARA, Karhumäki L, Ahola T, et al. Blood gases in orthostatic and exercise tests in patients with hyperventilaorthostatic and exercise tests in patients with

9 Gardner WN, Meah MS, Bass C. Controlled study of respiratory responses during prolonged measurement in patients with chronic hyperventilation. Lancet 1986;ii:82630.

10 Kinnula VL, Sovijärvi ARA. Elevated ventilatory equivalents during exercise in patients with hyperventilation syndrome. Respiration 1993;60:273-8.

11 Pitts F, McClure J. Lactate metabolism in anxiety neurosis. N Engl Med F 1967;277:1329-36.

12 Woods S, Charney D, Loke J, et al. Carbon dioxide sensitivity in panic disorder. Arch Gen Psychiatry 1985;43:900-9.

13 Sovijärvi ARA, Malmberg LP, Reinikainen K, et al. A rapid dosimetric method with controlled tidal breathing for histamine challenge: repeatability and distribution of bronchial reactivity in a clinical material. Chest 1993;104:164-70.
14 World Health Organisation. The ICD-10 classification of mental and behavioural disorders. Diagnostic criteria for

15 Quanjer PH, Tammeling GJ, Cotes JE, et al. Lung volumes and forced expiratory flows. Official statement of the European Respiratory Society. Eur $\mathcal{F}$ Respir 1993;6(Suppl 16):5-40.

6 Thulesius O. Orthostatic circulatory disturbances. Triangle 1970;9:258-64.

17 Wasserman K, Hansen J, Derryl Y, et al. Principles of exercise esting and interpretation. Philadelphia: Lea \& Fabiger, 1987.

18 Grossman P, deSwart J. Diagnosis of hyperventilation syndrome on the basis of reported complaints. F Psychosom Res 1984;28:97-104.

19 Gardner WN. The pathophysiology of hyperventilation disorders. Chest 1996;109:516-34.

20 Matalon S, Farhi LE. Cardiopulmonary readjustments in passive tilt. F Appl Physiol 1979;47:503-7. 